\title{
PROBING OF STUDENT POPULATION ATTITUDE TOWARDS CONTENT OF DBBT MASTER STUDY AS AN INDICATOR OF TRENDS IN IT LABOR MARKET
}

\author{
Ranko Babić ${ }^{1}$ \\ Branimir Jakšić ${ }^{1}$ \\ Siniša $\|_{1 i c^{*}}$, \\ Mile Petrović ${ }^{1}$
}

${ }^{1}$ Faculty of Technical Sciences, University in Pristina, Kosovska Mitrovica, Serbia, Kosovo

\begin{abstract}
:
Advances in IT technology inspired us to broaden McLuhan rule "the medium is the message" and to propose that permanent availability of smartphone is a new medium. All smartphone medium aspects heavily influence user habits which shapes their attitude to IT technology and, hence, to IT labor market. To make a preliminary test of such views, we constructed and carried out a questionaire among future students of DBBT (Digital Broadcast Broadband Technologies) Master programme of study, within the project Erasmus+. Our findings, extracted from two student groups, indicate prominent features which should be taken into account when assessing trends in IT labor market. We confirmed our findings by the third - control group of students.
\end{abstract}

Keywords:

questionarie, labor market, McLuhan, multimedia.

\section{INTRODUCTION}

A student of today is an employee of tomorrow - a trivial truth but a very important relationship, since present attitude of a student towards forms and contents delivered by and through IT gadgets would determine his future attitude towards offers on IT labor market. We aim to elaborate on (and examine) such a relationship in this paper.

Taking the medium or presentation aspect of IT technology one can say it is determined by itself - because it influences and even shapes user perception and IT habits.

Considering the forms by which television and computer present information, Marshall McLuhan had formulated the famous and prophetic remark "the medium is the message" [1]. Today, it is more than a remark - it is also a warning. A common user, being dominated by its vision for over $95 \%$ of the whole sensory input, is fully accustomed to visual sensations, treating it as something quite natural. In other words, it usually does not notice the act of seeing. So its vision is an open door to visual form of information which it receives through screens, displays etc. In some better case, a user is not aware that the very visuality of the message is some sort of a message, similarly as graphicality of newspapers or soundness of the radio. We can say it is an additional message in the message itself.

Aside from the visually dynamic form of presented messages, TV provides a passive steaming of (visual) messages. The nature of TV as a
Correspondence:

Ranko Babić

e-mail:

babic57@mts.rs 
medium is enhanced by the fact that a new (piece of) message arives almost instantly after the preceding one, not even allowing the subject to interpret or process it, since the visual influx overwhelms the capability to think about the content. This phenomenon we can an additional dimension of TV medium.

Smartphone is a combination of a computer, with visual appliance to communicate with the user, TV set and, finally, a phone.

Computer ability involves interaction with user-smartphone, which is a completely new medium, despite the fact that it communicates to the user through a visual display. Since it is a very complex phenomenon, we will elaborate on it in future papers.

Here we want to point out another medium aspect of a smartphone, which means a new message within the presented message.

It is the mobility of smartphone or, more precisely, its availability at any moment. It is pretty different comparing to conventional TV. A user must be present in front of a TV set to watch a TV programme. Although it is able to switch channels (programs), it does not influence or change the presentation capabilities of the TV itself. But the feature "mobility = availability" adds a new opportunity which means quite a different dimension of visual presentation on the smartphone display.

All preceding aspects of basically visual medium inevitably influence user habits and shapes its style of using it. Here, and always, we must remember the striking quote "We shape our tools and afterwards our tools shape us" [2], obviously inspired by M. McLuhan work.

Having all previous issues in mind we decided to carry out research to examine the validity of our observations. Methodology, at the beginning, included student population as a test sample and questionnarie as a probing method.

We considered that students of technical disciplines, which were chosen as samples, and among that, of electrical enginnering, informatics and computing, are pretty representative for such purpose.

\section{FEATURES OF STUDENT SAMPLE POPULATIONS}

The size of the sample, i.e. population of students, which was examined in this work, is 89 in total when Faculty of Technical Sciences in Kosovska Mitrovica (FTNKM) is regarded. The structure of the sample, in respect to the study profile, which we consider as an important feature, is given in Table 1,

\begin{tabular}{rcccc}
\hline Table 1 & & & & \\
\hline SPM & ET & CI & EN & TNoS \\
\hline NoS & 23 & 48 & 18 & 89 \\
\hline
\end{tabular}

where: SPM stands for Study Programme Module, ET - Electronics\&Communications, CI Computing\&Informatics, EN - Electroenergetics, (T) NoS - (Total) Number of students.

The questionnaire was held on September 19-22, 2016.

Another aspect of population, which would be significant for this examination, is the study year (SY) distribution of student population, over all study profiles, is given in Table 2.

\begin{tabular}{cccccc}
\hline Table 2 & & & & & \\
\hline SY & I & II & III & IV & I-IV \\
\hline NoS & 30 & 16 & 28 & 15 & 89 \\
\hline
\end{tabular}

We gave a similar survey for the sample student population in the Higher Technical Professional School in Zvečan (HTPSZ), which also participated in the questionnaire. The student population sample profile is given in Table 3,

\begin{tabular}{ccccccc}
\hline Table 3 & & & & \multicolumn{2}{c}{ NoS/Y } \\
\hline SPM & MEE & EN & PM & ITE & OP & \\
\hline SYI & 1 & 1 & 4 & 4 & 15 & 25 \\
\hline SYII & 0 & 3 & 3 & 1 & 13 & 20 \\
\hline SYIII & 0 & 2 & 2 & 5 & 7 & 16 \\
\hline NoS/P & 1 & 6 & 9 & 10 & 35 & $\mathbf{6 1}$ \\
\hline
\end{tabular}

where: MEE - Management of Electrical Engineering, EN - Electroenergetics, PM - Production Management, ITE - Information Technology Engineering, OP - Other study programmes, NoS/Y(NoS/P) - Number of Students per Year (per Study Programme).

\section{PREPARATION OF QUESTIONNAIRE}

\section{Preparation Methodology}

In order to attain as intrinsic results as possible, we created a questionary which was apparently related to a new DBBT master study programme, in the frame of ERASMUS+ project, intended to acreditation. Aside from the recommendations for making the questionnaire, [3], 
[4], [5], our questions were formulated so as to have two layers, the surface one, which respected the DBBT master study module itself, and a hidden one, which would reflect our research intention to detect the mode of student population which we could withdraw some correlations for IT labor market from.

The preparation of questions was obviously based on estimated features of population samples and aimed at expressing students' attitude to medium characteristics as explained previously.

Populations (profiles, motivation, conditions of study - 3 or 4 years) were different, the fact they entered the school already qualifies them in the aspect of readiness.

Therefore, questions for different populations on FTNKM and on HTPSZ are pretty similar despite the fact the populations are different, either in respect of offered study profiles at both HEI (High Education Institutions) or expected mode of study (e.g. duration of study).

\section{Questions, answers and data}

Here we presented all questions to illustrate our idea of two-layered formulation. Above that, the whole questionnaire is two-layered so as to attain the general effect.

We did not pay attention to the order of questions, in the sense that the answers would depend on the question sequence. Maybe such an effect is worth considering for a more numerous population, and it is left for further research.

The question order, 1, 2, 3, 4, 5, 7, 8, 10 and the questions itself, were the same in FTNKM and in HTPSZ. The rest were formulated and positioned differently, as we have shown below.

The offered answers were gradual, in order to extract as much information as possible. For the sake of compactness, in this paper they are presented in tables as abbreviated labels, and equalised with offered answers in the HTPSZ questionnaire, which was formulated in a different way (see Table 4).

\begin{tabular}{cll}
\hline Table 4 & \multicolumn{2}{l}{ offered answers } \\
\hline $\boldsymbol{A} \boldsymbol{b} \boldsymbol{b}$ & FTNKM & HTPSZ \\
\hline no & no & not interested at all \\
\hline pn & partly no & neither interested nor disinterested \\
\hline mb & maybe & partly interested \\
\hline py & partly yes & interested \\
\hline Yes & yes & completely interested \\
\hline
\end{tabular}

Answers offered using a scale were had the purpose to unify the answers in order to facilitate merging of both populations in the processing of results.

In order to present questionnaire statistics so as to provide an appropriate appearance for an effective survey and analysis, we derived shortened versions of questions, to be put into the table and to remind the analyst of the full question formulation. All shortened versions are given below.

Q1. (the first question) Would you like to learn how to work with the audio and video equipment in the multimedia HDTV studio? (for short in Table 6: work in TV studio)

In Table 5 we present answer statistics only for this question

Table 5 answers stat for Q1 “work in TV studio"

\begin{tabular}{cccccc}
\hline$\%$ & no & pn & mb & py & yes \\
\hline FTN & 4 & 1 & 15 & 28 & 52 \\
\hline HTPSZ & 6,6 & 11,5 & 27,9 & 26,2 & 27,9 \\
\hline
\end{tabular}

Q2. Are you interested in participating in a project which is immediately applicable in practice? (project in practice)

Statistics for Q2 is given in the main table, Table 6, as well as for other questions.

Q3. Would you like to learn how to film a TV content, how film material is edited, visual effects created, TV formats produced? (make TV, flim)

Q4. Are you interested in learning how to produce earth and satellite radio and HDTV signal transfer, through text, audio and visual explanations and through adequate software and laboratory exercises? (signal transmission)

Q5. Are you interested in how mobile TV functions, through explanations and laboratory demonstrations? (mobile TV functioning)

Q7. Are you interested in learning and acquiring practical experience in sound processing in laboratories? (sound processing)

Q8. Would you like to learn and acquire practical experience in image and video content processing? (image video processing)

Q10. Are you interested in performing professional practice or writing your thesis in a company which specializes in the area of the specialist professional study programme that you have completed? (thesis/practice)

Questions which appeared only in HTPSZ questionnaire are: 
Q6-H. Are you interested in the specialist professional studies where practical application of tools in producing a TV content is learned? (tools in TV production)

Q9-H. Are you interested in learning how to measure the strength and the quality of the emitted signal and admission signal? (signal measurement)

Questions which appeared only in FTNKM questionnaire:

Q6-F. Are you curious to understand how IP phone or IPTV work? (work of IP phone/IPTV)

Q9-F. Are you interested in master studies where you develop applications for smart TV, Android, computer games? (Android applications, games)

\begin{tabular}{lccccc}
\hline \multicolumn{7}{l}{ Table $6 \quad$ answer statistics in \% } & \multicolumn{2}{l}{ (FTN/ HPS) } \\
\hline question / answer & no & pn & mb & py & yes \\
\hline work in TV studio & $4 / 7$ & $1 / 11$ & $15 / 28$ & $28 / 26$ & $52 / 28$ \\
\hline make TV, flim & $4 / 2$ & $5 / 16$ & $11 / 20$ & $17 / 34$ & $63 / 28$ \\
\hline image, video processing & $5 / 0$ & $3 / 12$ & $20 / 21$ & $18 / 38$ & $54 / 29$ \\
\hline signal transmission & $4 / 3$ & $6 / 15$ & $17 / 38$ & $21 / 26$ & $52 / 18$ \\
\hline mobile TV functioning & $2 / 5$ & $5 / 16$ & $20 / 26$ & $20 / 23$ & $53 / 30$ \\
\hline thesis/practice & $1 / 0$ & $0 / 2$ & $18 / 21$ & $18 / 36$ & $63 / 41$ \\
\hline project in practice & $5 / 0$ & $3 / 7$ & $15 / 31$ & $29 / 33$ & $48 / 29$ \\
\hline sound processing & $5 / 3$ & $11 / 3$ & $31 / 26$ & $17 / 44$ & $36 / 25$ \\
\hline work of IP phone/IPTV & $1 /-$ & $1 /-$ & $10 /-$ & $38 /-$ & $50 /-$ \\
\hline Android apps, games & $3 /-$ & $1 /-$ & $15 /-$ & $11 /-$ & $70 /-$ \\
\hline tools in TV production & $-/ 0$ & $-/ 10$ & $-/ 33$ & $-/ 30$ & $-/ 28$ \\
\hline signal measurement & $-/ 3$ & $-/ 16$ & $-/ 33$ & $-/ 25$ & $-/ 23$ \\
\hline
\end{tabular}

\section{ANALYSIS OF RESULTS}

The Table 6 speaks for itself showing that students are more (mostly) inclined toward more visual than brain tedious activities, in the visually dominant mode of information presentation. One should not oversee an important factor which influences, or to put it better, determines such an attitude: long-term influence of GUI, with its main goal to restrain user memory and brain engagement during interaction, to govern the user by graphical elements presented on display, which reminds the user step-by-step what to do.

Our conclusions are confirmed by another questionnaire, conducted at The School of Electrical and Computer Engineering of Applied Studies (Belgrade), which served as the control sample, involving 56 students. Questions were formulated more explicitly and the offered answers were binary (yes/no).
In the following we quote the questions and percentage of binary answers.

Would you enroll in two-year master studies of audio and video technologies? (yes 91\% ; no 10\%)

Would you enroll in AVT master studies whose program would comprise more technical courses and mathematics? (yes $47 \%$; no $53 \%$ )

Would you enroll in AVT master studies whose program would comprise more art courses? (yes $89 \%$; no $11 \%)$

Would you enroll in AVT master studies whose program would comprise more humanistic courses of journalism and production? (yes 65\% ; no 35\%)

Would you enroll in AVT master studies which program would comprise more humanistic courses of journalism and production? (yes 65\% ; no 35\%)

Would you enroll in AVT master studies which program would be multidisciplinary and comprise technical, art and humanistic courses of journalism and production of digital media? (yes $72 \%$; no $28 \%$ )

Would you enroll in the master studies, exclusively oriented to technical and engineering courses? (yes 49\% ; no 51\%)

Would you enroll in the master studies, exclusively oriented to art courses? (yes $75 \%$; no $25 \%$ )

Methodologically speaking, the control group in Belgrade may seem as inappropriate because of different regional conditions which affected the education process during schooling.

But for the purposes of this investigation the chief factors which determine profiling of population are influence of GUI and smartphones (at least for last two years) for which a simple estimation confirms to be the same. The second level factors are also very similar since these student populations (from Kosovska Mitrovica and Belgrade) were exposed to equal conditions during their undergraduate studies, within similar study programmes.

\section{CONCLUSION}

In this research we started with a moderate aim to find some correlations between attitude towards IT technology in student population and their expected readiness to accept certain forms on IT labor engagement. Although (available) sample sizes were moderate in respect to carefully constructed questionnaires we think we reached valuable data and confirmed what we had expected. Here it is not the question whether today's students will be not 
accept some labor market offers and work profiles. They will certainly accept them after all, because they need to earn their living.

But we aimed to find out which labor forms and profiles they would accept more readily or promptly in accordance with their intimate wishes, which would motivate them to perform better. Motivation is another name for work effectiveness.

These preliminary results would spur us to continue, broaden and refine our further research and investigation.

Another direction of further research is our proposal to treat non-obvious aspects of smartphone as medium and to find methodology on how to examine its essence and ways in which it influences the user.

\section{ACKNOWLEDGMENT}

The questionnaire in this paper is carried out within the project Implementation of the study program - Digital Broadcasting and Broadband Technologies (DBBT Master studies), Erasmus+ CBHE Project No. 561688-EPP1-2015-1-XK-EPPKA2-CBHE-JP.

\section{REFERENCES}

[1] McLuhan, Marshall, Understanding Media: The Extensions of Man, McGraw-Hill, 1964

[2] Culkin, J.M., A schoolman's guide to Marshall McLuhan. Saturday Review (1967, March 18), pp. $51-53,71-72$

[3] Dillman, Don A., Smyth, Jolene D., Christian, Leah Melani, Internet, Phone, Mail and Mixed-Mode Surveys: The Tailored Design Method, 4th edition. John Wiley: Hoboken, NJ 2014

[4] Saris, W. E. and Gallhofer, I. N., Design, evaluation and analysis of questionnaires for survey research, Second Edition. Hoboken, Wiley 2014

[5] Shaughnessy, J.; Zechmeister, E.; Jeanne, Z., Research methods in psychology (9th ed.). New York, NY: McGraw Hill 2011, pp. 161-175. 